\title{
D - lactic acid production from waste paper by recombinant Escherichia
}

\section{coli JH13}

\author{
Ye $\mathrm{Liu}^{1, \mathrm{a}}$, Xiangmin $\mathrm{Fu}^{1, \mathrm{~b}}$, Yongze Wang ${ }^{1, \mathrm{c}}$, Jinhua Wang ${ }^{\star 1, \mathrm{~d}}$ \\ ${ }^{1}$ Hubei Provincial Cooperative Innovation Center of Industrial Fermentation, Key Laboratory of \\ Fermentation Engineering (Ministry of Education), College of Bioengineering, Hubei University of \\ Technology, Wuhan 430068, P. R. China \\ a18771014396@163.com, b332947713@qq.com, cwyzzju@126.com, \\ *dwangjinhua@mail.hbut.edu.cn
}

Keywords: waste office paper; waste newspaper; hydrolysate; D-lactic acid

Abstract: Waste paper as a new kind of biomass resource was selected as the research object to ferment and produce D-lactic acid in this paper. The components of raw materials were compared between waste office paper and waste newspaper, which were pretreated by shredding, $3 \% \mathrm{H}_{2} \mathrm{SO}_{4}$ and enzymatic hydrolysis. The hydrolysate could be used as single carbon source for lipid fermentation by Escherichia coli JH13. Shake-flask fermentation was carried out to produce D-lactic acid by Escherichia coli JH13 using the hydrolysate of waste office paper and waste newspaper as carbon source. Fermentation with waste office paper and waste newspaper hydrolysate as carbon source achieved a D-lactic acid production of $35.86 \pm 0.62 \mathrm{~g} / \mathrm{L}$, which was $39.8 \%$ higher than the D-lactic acid production $(25.64 \pm 0.48 \mathrm{~g} / \mathrm{L})$ with waste newspaper hydrolysate as carbon source.

\section{Introduction}

D-lactic acid was widely used in pharmaceutical and pesticide as the synthetic precursor of many chiral compounds. High optical purity D-lactic acid and methanol can esterify to produce D-lactic acid methyl ester, which can be used to compound R-1,2-propylene glycol, R-2-hydroxycarboxylate and Instead of proline etc. These chiral compounds were midbody of vital pharmaceuticals $^{[1]}$. Aromatic propionic acid herbicide was the pioneer realized industrial production and was increasingly widespread used in agriculture recently. D-lactic acid was the optical active precursor of chloropropionic acid, which was the material of this type of herbicide ${ }^{[2]}$.

In recent years, lactic acid as a vital product has attracted considerable attention for its wide spread applications. in cosmetic product, pharmaceutical and chemical industries ${ }^{[3]}$, the most important application is the polymerization to polylactic acid(PLA), which is a renewable, environmentally friendly biodegradable plastics. The expanding applications of PLA are in the industrial packaging field and the biocompatible medical device market ${ }^{[4]}$. About $90 \%$ of the worldwide lactic acid production comes from microbial fermentation because the biological production results in optical pure D or L-lactic acid and it is possible to use renewable raw material as substrate ${ }^{[5]}$.

Many chemicals can be produced from renewable lignocellulose materials carbohydrates using microbial fermentation. With the increases in petroleum costs recent have created an opportunity for agro-products to be cost-competitive with petroleumbased products. Lignocellulose materials as a potential source of ethanol has recently gained considerable interest in Asian countries ${ }^{[6]}$. Waste 
paper as one of the lignocellulose materials is an abundant renewable resource, that the main hydrolysate are glucose and xylose which can be applied to fermentation.

In this paper, waste office paper and waste newspaper were subjected acidolysis followed by enzymolysis pretreatments. The hydrolysate was applied to produce D-lactic acid as the inexpensive carbon source. The production of D-lactic acid by Escherichia coli $\mathrm{JH} 13$ was investigated using flasks.

\section{Materials and methods}

Raw materials Waste office paper and newspaper were collected from offices of Hubei University Of Technology. The waste office paper and waste newspaper were shredded pieces by shredder and air dried at $60{ }^{\circ} \mathrm{C}$. The contents of cellulose and hemicellulose in waste office paper and waste newspaper were determined using the method of Sluiter et. al (A. sluiter, 2012). The shattered waste office paper and newspaper were subjected a two-step acidolysis followed by enzymolysis treatment. In acidolysis, 3\% sulfuric acid was used with 1:10 (w/v) to liquefy and hydrolyze the fresh material. The cellulase (30 FPU/g) was applied in the enzymolysis process with reacting $48 \mathrm{~h}$ at $140 \mathrm{rmp}$.

Microorganisms and production medium Escherichia coli JH13 is a strain which can produce D-lactic acid, was provided by Key Laboratory of Fermentation Engineering of Hubei University of Technology. The strain was stored in $40 \%$ glycerol at $-80{ }^{\circ} \mathrm{C}$, and activated three times by streaking it out on Luria-Bertani (LB) agar plates and incubating at $37^{\circ} \mathrm{C}$ for $24 \mathrm{~h}$.

Fermentation process of D-lactic acid in flasks by $E$. coli JH 13 Transferring one colony from a slant to $50 \mathrm{~mL}$ of LB broth medium with an addition of $20 \mathrm{~g} / \mathrm{L}$ xylose as starter cultures, followed by incubation at $37{ }^{\circ} \mathrm{C}$ and $150 \mathrm{rpm}$ until the OD reached 1.0-1.5. The medium for D-lactic acid fermentation consisted of the following ingredients $(\mathrm{g} / \mathrm{L})$ : hydrolysate of waste paper, tryptone 10 $\mathrm{g} / \mathrm{L}$ and yeast extract $5 \mathrm{~g} / \mathrm{L}$. The initial $\mathrm{pH}$ of all media was adjusted to 7.0 with $\mathrm{NaOH}$. All culture media were autoclaved at $115{ }^{\circ} \mathrm{C}$ for $20 \mathrm{~min}$. Working volumes of the $250 \mathrm{~mL}$ flasks were $100 \mathrm{~mL}$ and inoculum size of fermentations for production of D-lactic acid by E. coli JH 13 was $2 \%(\mathrm{v} / \mathrm{v})$. The fermentation was carried out under anaerobic condition at $37{ }^{\circ} \mathrm{C}$ and agitation speed $150 \mathrm{rpm}$. Samples were withdrawn periodically from the culture broth to determine the production of D-lactic acid.

Analysis Filtered the supernatant through a $0.22 \mu \mathrm{m}$ membrane (Millipore, USA) for HPLC analysis after cells removing. The concentrations of glucose, xylose, lactic acid and other organic acid byproducts were determined by HPLC equipped with a Bio-Rad HPX 87H column and a differential refracting index detector (RID-6A, Shimadzu). The analytical conditions were as follows: column temperature, $40{ }^{\circ} \mathrm{C}$; mobile phase, $4 \mathrm{mM} \mathrm{H}_{2} \mathrm{SO}_{4}$; flow rate, $0.5 \mathrm{~mL} / \mathrm{min}$.

\section{Results and discussion}

The component analysis of cellulose, hemicellulose and lignin contents inoffice paper and newspaper The contents of cellulose, hemicellulose and lignin in waste office paper and newspaper were determined using the method of Sluiter et. Al (A. sluiter, 2011). The results were shown in table 1. The cellulose, hemicellulose and lignin in waste office paper were $79.34 \pm 0.72 \%$, $13.92 \pm 0.51 \%$ and $3.18 \pm 0.45 \%$, whereas those in waste newspaper were $67.52 \pm 0.83 \%, 20.23 \pm 0.54 \%$ and $9.15 \pm 0.67 \%$. The cellulose content in waste office paper was relative higher than waste newspaper, while the hemicellulose and lignin contents were lower than waste newspaper. 
Table 1 Component differences between waste office paper and waste newspaper

\begin{tabular}{ccc}
\hline Component & $\begin{array}{c}\text { Office paper } \\
(\%)\end{array}$ & $\begin{array}{c}\text { Newspaper } \\
(\%)\end{array}$ \\
\hline Cellulose* & $70.12 \pm 0.53$ & $61.81 \pm 0.72$ \\
Hemicellulose* & $13.71 \pm 0.60$ & $20.64 \pm 0.47$ \\
Lignin* & $9.85 \pm 0.39$ & $10.34 \pm 0.51$ \\
\hline
\end{tabular}

* indicates significant difference at $\mathrm{P}<0.05$ level.

The sugar contents in hydrolysate The sugar content in hydrolysate was analysed after acidolysis and enzymolysis, and the results were shown in table 2. Total sugar content in waste office paper was $40.02 \pm 1.09 \mathrm{~g} / \mathrm{L}$, higher than waste newspaper which was $35.25 \pm 1.41 \mathrm{~g} / \mathrm{L}$ obviously. The glucose content in waste office paper was $28.36 \pm 0.95 \mathrm{~g} / \mathrm{L}$, which was higher than the content in waste newspaper $(22.73 \pm 0.5635 .25 \mathrm{~g} / \mathrm{L})$, while the contents of xylose and arabinose in waste newspaper were $10.06 \pm 0.25$ and $1.45 \pm 0.32 \mathrm{~g} / \mathrm{L}$, higher than that in waste office paper $(8.33 \pm 0.51$ and $0.96 \pm 0.14 \mathrm{~g} / \mathrm{L})$.

Table 2 Comparison of hydrolysate of waste office paper and newspaper

\begin{tabular}{ccccc}
\hline \multirow{2}{*}{ Material } & \multicolumn{3}{c}{ Sugar compositions after enzymatic hydrolysis (g/L) } \\
\cline { 2 - 5 } & Glucose $^{*}$ & Xylose* & Arabinose* $^{*}$ & Total sugar* \\
\hline Office paper & $28.36 \pm 0.95$ & $8.33 \pm 0.51$ & $0.96 \pm 0.14$ & $40.02 \pm 1.09$ \\
Newspaper & $22.73 \pm 0.56$ & $10.06 \pm 0.25$ & $1.45 \pm 0.32$ & $35.25 \pm 1.41$ \\
\hline
\end{tabular}

* indicates significant difference at $\mathrm{P}<0.05$ level.

Fermentation process of D-lactic acid in flasks by $E$. coli JH 13 The hydrolysate of waste office paper and waste newspaper were applied as carbon source in the following fermentation by E. coli JH 13. The time course for total sugar, glucose and xylose consumption, D-lactic acid production were shown in figure 1. During the first $24 \mathrm{~h}$, time course for sugar and glucose consumption were similar, while xylose was hardly used. The values of sugar and glucose consumption increase significantly from $12 \mathrm{~h}$ to $24 \mathrm{~h}$, yet xylose was used up rapidly from $24 \mathrm{~h}$ to $48 \mathrm{~h}$. In the first $24 \mathrm{~h}$ in fermentation process, glucose was almost consumed completely both in waste office paper hydrolysate and waste newspaper hydrolysate. After $24 \mathrm{~h}$, xylose was consumed and almost be used completely at $48 \mathrm{~h}$ both in two hydrolysate. The D-lactic acid content of waste office paper and waste newspaper increased significantly and reached the maximum value at $36 \mathrm{~h}$, after which it no longer increased. The maximum D-lactic acid content value of waste office paper was $35.86 \mathrm{~g} / \mathrm{L}$ which was $39.8 \%$ higher than that of waste newspaper $(25.64 \mathrm{~g} / \mathrm{L})$.
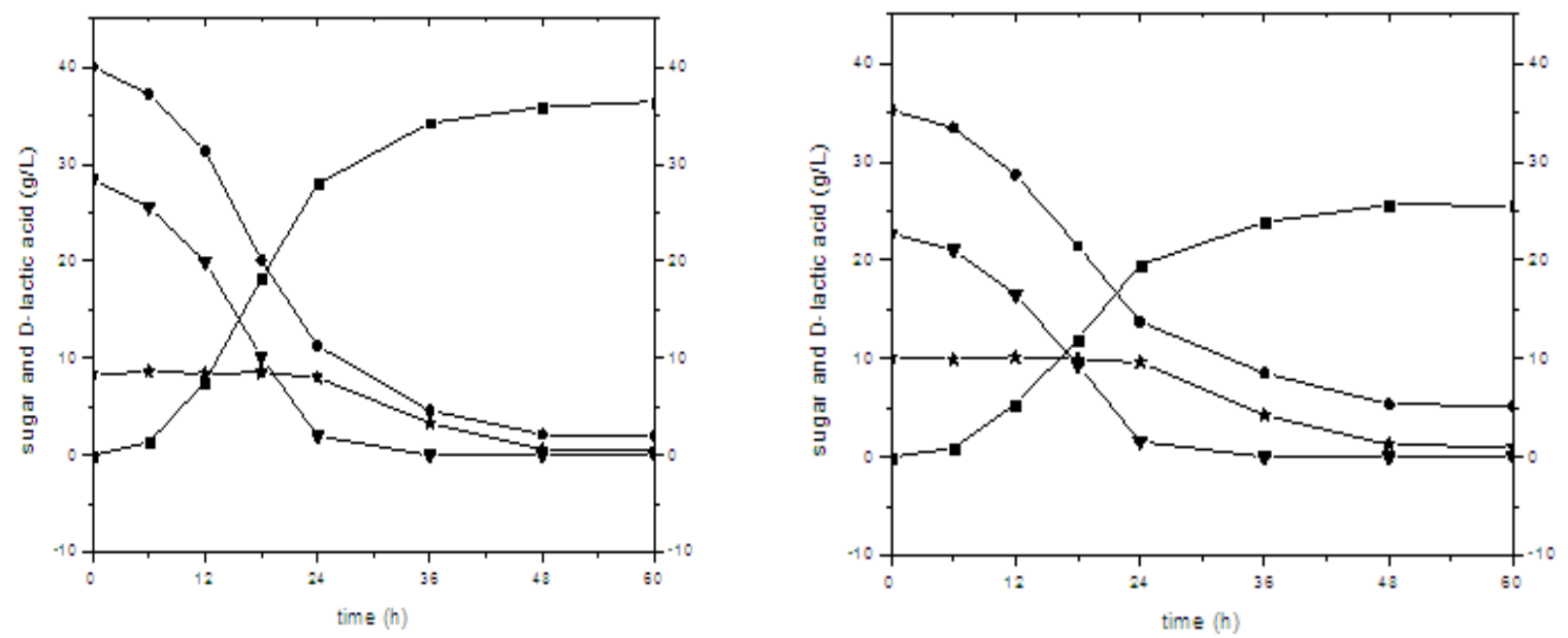

Figure 1 Time course of D-lactic acid production by E. coli JH13 with waste office paper and waste 
newspaper hydrolysate at $\mathrm{pH} 7.0$ and $37^{\circ} \mathrm{C}$. A: brittle rice straw; B: Normal straw. (匹,total sugar; $\bullet$, glucose; $\boldsymbol{\Lambda}$, xylose; $\downarrow$ D-lactic acid)

\section{Conclusions}

Waste office paper hydrolysate contains relative higher total sugar, glucose but lower xylose compared with, after pretreated by sulfuric acid and cellulase. Cellulose content in waste office paepr is $17.5 \%$ higher than waste newspaper, while hemicellulose content is lower than waste newspaper. Both the waste office paper and waste newspaper hydrolysate could be used as carbon source to produced D-lactic acid by E. coli $\mathrm{JH} 13$, and glucose was used prior to xylose during the process. The hydrolysate of waste office paper was more suitable for production of D - lactic acid than waste newspaper, as the maximum D-lactic acid content value of waste office paper was 35.86 $\mathrm{g} / \mathrm{L}$ which was $39.8 \%$ higher than that of waste newspaper $(25.64 \mathrm{~g} / \mathrm{L})$. Toxic substances content various in hydrolysate of different lignocellulose materials, and the inhibiting effect to $E$. coli JH13 were different. (Palmqvist, E., \& Hahn-Hägerdal, B. 2000)

Our study provides theoretical basis for application of waste paper and expands the usage of mixed office waste.

\section{Acknowledgements}

This research was supported by the National Science \& Technology Pillar Program during the 12th Five-year Plan Period (Grant No. 2012BAD27B03), Nature Science Foundation of HuBei Province (Grant No.2011CDB076), Doctoral Scientific Research Foundation of HuBei University of Technology (Grant No. BSQD12047, No. BSQD12143 and No. BSQD13005).

\section{References}

[1] Nájera C, de Gracia Retamosa M, Sansano J M. 1, 3-Dipolar cycloadditions of azomethine ylides with chiral acrylates derived from methyl (S)-and (R)-lactate: diastereo-and enantioselective synthesis of polysubstituted prolines[J]. Tetrahedron: Asymmetry, 2006,17(13): 1985-1989.

[2] Metivier P, Rajoharisson H. Process for the preparation of optical isomers of 2-chloropropionic acid esters: U.S. Patent 5,049,676[P]. 1991-9-17.

[3] Abdel-Rahman M A, Tashiro Y, Sonomoto K. Recent advances in lactic acid production by microbial fermentation processes[J]. Biotechnology advances, 2013, 31(6): 877-902.

[4] Agrawal A K, Bhalla R. Advances in the production of poly (lactic acid) fibers. A review[J]. Journal of Macromolecular Science, Part C: Polymer Reviews, 2003, 43(4): 479-503.

[5] Hofvendahl K, Hahn-Hägerdal B. Factors affecting the fermentative lactic acid production from renewable resources 1[J]. Enzyme and microbial technology, 2000, 26(2): 87-107.

[6] Karimi K, Emtiazi G, Taherzadeh M J. Ethanol production from dilute-acid pretreated rice straw by simultaneous saccharification and fermentation with Mucor indicus, Rhizopus oryzae, and Saccharomyces cerevisiae[J]. Enzyme and Microbial Technology, 2006, 40(1): 138-144. 